\title{
(RE)CONSTRUINDO VÍNCULOS: RELATO DE EXPERIÊNCIA DE UM GRUPO DE APOIO À ADOÇÃO
}

\author{
Patricia Santos da Silva \\ Mônica Sperb Machado \\ Monique Schwochow Silberfarb \\ Roberta Stefanini Machemer \\ Aline Talita Rosa dos Santos \\ Universidade Federal do Rio Grande do Sul, Porto Alegre-RS, Brasil \\ Veronica Petersen Chaves \\ Tribunal de Justiça do Rio Grande do Sul, Porto Alegre-RS, Brasil \\ Giana Bitencourt Frizzo \\ Universidade Federal do Rio Grande do Sul, Porto Alegre-RS, Brasil
}

\begin{abstract}
RESUMO
A construção dos vínculos na adoção é um processo complexo, com momentos de fragilização emocional para os adultos e para as crianças e adolescentes, porém os serviços de suporte às famílias no pós-adoção ainda são escassos. Estudos internacionais apontam para a necessidade de apoio sentida pelas famílias em processo de adoção e os Grupos de Apoio à Adoção (GAA) têm sido uma modalidade importante de suporte no Brasil. Pensando na importante contribuição que os GAA podem exercer nas famílias por adoção, este estudo pretende descrever a experiência de uma parceria entre Universidade e uma ONG Sul-brasileira durante o período de um ano, na condução dos trabalhos do grupo. Os encontros aconteceram mensalmente e foram conduzidos por estudantes de pós-graduação com experiência clínica e de pesquisa na área da adoção e os temas dos encontros eram escolhidos pelas próprias famílias participantes. A experiência permitiu evidenciar a potência do grupo ao incentivar que sentimentos e dúvidas fossem relatados em um ambiente acolhedor e sem julgamentos, o que contribuiu para a desmistificação de temas relacionados à adoção e, possivelmente, para a construção e fortalecimento dos vínculos com as crianças e com outras famílias.
\end{abstract}

Palavras-chave: Adoção (criança); Parentalidade; Relações familiares; Família; Psicologia jurídica. 


\section{(RE)BUILDING BONDS: EXPERIENCE REPORT OF A SUPPORTING GROUP FOR ADOPTION}

\section{Abstract}

Forming bonds in adoption is a complex process, with moments of emotional fragility for adults and for children and adolescents, but services to support families in the postadoption period are still scarce. International studies point to the need for support felt by families in the process of adoption and Adoption Support Groups (GAA, in Portuguese) have been an important modality of support in Brazil. Bearing in mind the important contribution that GAA can make to families by adoption, this study intends to describe the experience of a partnership between the University and a South-Brazilian ONG (in Portuguese) during a one-year period, in conducting the group's work. The groups took place monthly and were conducted by graduate students with clinical and research experience in the field of adoption. The themes of the meetings were chosen by the participating families themselves. The experience showed the power of the group to encourage families to report feelings and doubts in a welcoming and non-judgmental environment, which contributed to the demystification of themes related to adoption and, possibly, to the construction and strengthening of bonds with children and with other families.

Keywords: Adoption (child); Parenting; Family relationship; Family; Forensic psychology.

\section{(RE)CONSTRUYENDO VÍNCULOS: RELATO DE EXPERIENCIA DE UN GRUPO DE APOYO A ADOPCIÓN}

\section{RESUMEN}

La construcción de vínculos durante la adopción es un proceso complejo, con momentos de debilidad emocional para adultos y para niños y adolescentes, pero los servicios de apoyo a las familias en el período posadopción aún son escasos. Estudios internacionales apuntan a la necesidad de apoyo que sienten las familias en el proceso de adopción y los Grupos de Apoyo a la Adopción (GAA) han sido una modalidad importante de apoyo en Brasil. Teniendo en cuenta la importante contribución que GAA puede hacer a las familias por adopción, este estudio pretende describir la experiencia de una asociación entre la Universidad y una ONG del sur de Brasil durante un período de un año, en la conducción del trabajo del grupo. Los grupos se realizaron mensualmente y fueron conducidos por estudiantes graduados con experiencia clínica y de investigación en el campo de la adopción y los temas de los encuentros fueron elegidos por las propias familias participantes. La experiencia mostró el poder del grupo para alentar sentimientos y dudas a ser reportados en un ambiente acogedor y sin prejuicios, lo que contribuyó a la desmitificación de temas relacionados con la adopción y posiblemente a la construcción y fortalecimiento de vínculos con los niños y con otras familias.

Palabras clave: Adopción (niños); Parentalidad; Relaciones familiares; Familia; Psicología jurídica. 
No Brasil, pais por adoção devem passar por um processo regulado pelo estado, denominado habilitação para adoção, que determina se os indivíduos poderão ou não adotar, baseado no princípio do melhor interesse da criança ou adolescente (Lei 8.069, 1990; Lei 12.010, 2009). Os pretendentes à adoção, após habilitados nos termos da lei, integrarão o Sistema Nacional de Adoção e Acolhimento (SNAA) onde aguardarão a indicação de uma criança disponível, conforme as características da criança escolhidas nesse processo (Resolução $\mathrm{N}^{\circ} 289,2019$ ). Entre o tempo de espera e o estágio em que se conhece a criança, em geral, passam-se alguns anos, de acordo com as características da criança desejadas pelos candidatos. Comumente, nesse período, muitos futuros pais procuram por grupos de apoio à adoção (Costa et al., 2011).

As crianças que esperam pela adoção, por seu histórico de vicissitudes vividas em um longo processo de rompimento de vínculos e de cuidados inadequados, geralmente trazem ao encontro com sua nova família importantes demandas de cuidado para a reconstrução de sua subjetividade. São crianças com necessidades de cuidados com relação a sua saúde física e mental, bem como com experiências e vivências de abandono, de violência e de longos períodos de institucionalização (Moyer \& Goldberg, 2015). Todos esses são fatores que tornam complexo o estabelecimento do apego entre pais e filhos.

Ainda, a legislação relacionada à adoção no Brasil prevê que os postulantes à adoção passem por um período de preparação psicossocial e jurídica, orientado pela equipe técnica da Justiça da Infância e da Juventude, com apoio dos técnicos responsáveis pela execução da política municipal de garantia do direito à convivência familiar, ainda durante o processo de habilitação para adoção (Lei 12.010, 2009; Silva et al., 2017). Porém, após a adoção se efetuar, com o deferimento da sentença final, as famílias encontram pouco apoio para lidar com as demandas da transição para a parentalidade adotiva (Silva, 2018). Esse período inicial que os pais passam com a criança é um momento delicado para estabelecer o primeiro contato como família e iniciar o processo de vinculação (Alvarenga \& Bittencourt, 2013). Apesar disso, serviços de suporte aos pais no pós-adoção ainda são escassos e deveriam estar disponíveis a longo prazo, além do período de estágio de convivência. Além disso, no Brasil, o apoio psicológico para famílias adotivas não é uma especificidade, nem mesmo nas práticas clínicas.

Estudos internacionais também apontam para a necessidade de apoio sentida pelas famílias em processo de adoção, como no Reino Unido, Irlanda (Weistra \& Luke, 2017), Estados Unidos (Burke et al., 2018; Miller et al., 2018; Waid \& Alewine, 2018) e Noruega (Bergsund et al., 2018). Uma modalidade importante de suporte que vem sendo relatada refere-se aos grupos de apoio à adoção. Dentre os efeitos positivos da participação em grupos estão: a redução de sintomas depressivos e ansiedade (Costa et al., 2011; Scorsolini-Comin et al., 2006; Weistra \& Luke, 2017); a revisão de crenças e preconceitos relacionados à adoção (Fiorott et al., 2019; Morelli et al., 2015; Sequeira \& Stella, 2014; Scorsolini-Comin et al., 2006; Weistra \& Luke, 2017); e o aprendizado para lidar com as demandas emocionais e comportamentais do filho adotivo (Cavarzan \& Camargo, 2017; Menezes \& Dias, 2018; Sequeira \& Stella, 2014). Contudo, apesar da literatura demonstrar que as famílias por adoção carecem de suporte e que a participação em grupos pode auxiliar, Miller et al. (2018) destacam que algumas podem não ter acesso aos grupos, ao passo em que o formato destes pode não atender as necessidades reais das famílias. Além disso, os autores referem lacunas na literatura de avaliação dos grupos, o que dificulta o emprego de metodologias eficazes.

Silva et al. (2022). (Re)construindo vínculos: relato de experiência de um grupo de apoio à adoção. https://doi.org/10.32467/issn.2175-3628v23n1a14 
No contexto nacional, a Associação Nacional de Grupos de Apoio para Adoção (ANGAAD) representa os grupos perante as autoridades públicas e organizações civil. Essa associação procura por suporte para investir e desenvolver ações relacionadas à adoção. A ANGAAD afirma que Grupos de Apoio para Adoção (GAA) usualmente são formados por iniciativas de pais adotivos, após a adoção, que trabalham voluntariamente para auxiliar outras famílias. De acordo com essa associação, os GAA têm a função de preparar adotantes, acompanhar pais adotivos após a adoção, prevenir fracassos na adoção, ajudar com a reintegração familiar, conscientizar a sociedade quanto à legitimidade da família adotiva, e, em alguns casos, mediar a busca ativa por famílias que possam adotar crianças que diferem do perfil usual desejado (ANGAAD, 2019).

GAAs brasileiros usualmente trabalham os aspectos emocionais relacionados à transição para a parentalidade adotiva promovendo debates sobre as experiências de famílias adotivas. Para aqueles que estão no aguardo pela adoção, os GAA servem como um espaço para refletir sobre a decisão de adoção e seus possíveis resultados (Sequeira \& Stella, 2014). Morelli et al. (2015) discutem que, ao participar de GAAs, possíveis pais são convidados a construir um "lugar" emocional para a criança adotiva, ou seja, construir a ideia de quem será esse filho em suas vidas e já se imaginarem como pais por adoção. Além disso, esses autores sugerem que participar de um grupo com esse propósito pode promover mudanças na maneira com que os futuros pais entendem a adoção e o que esperam na relação com seus filhos.

Também se fala do caráter humanitário dos GAA. Durante o processo legal no Brasil, muitos desses futuros pais não se sentem acolhidos pelos técnicos judiciários responsáveis pela habilitação para a adoção (Sequeira \& Stella, 2014). O estudo de Scorsolini-Comin et al. (2006) analisou qualitativamente um GAA na região sudeste do Brasil composto por 11 pessoas em diferentes estágios do processo de espera pela adoção. Para os autores, foi possível entender que, por meio do GAA, esses futuros pais adotivos se sentiam aliviados em encontrar pessoas com o mesmo desejo pela adoção. Esse alívio melhorou a autoestima dos futuros pais e reduziu o estigma em torno da adoção. Ainda, puderam observar a consolidação de um senso de esperança desses participantes ao ouvirem os relatos e resultados positivos de outros participantes dos grupos sobre seu processo de espera.

Com isso, alguns indivíduos se tornam participantes frequentes das reuniões dos GAAs. Os temas discutidos nos grupos que compuseram o estudo de Sequeira e Stela (2014) foram a elaboração da impossibilidade da filiação biológica, a desidealização da maternidade e paternidade, o apoio emocional durante o período de espera pela adoção e a desconstrução dos medos relacionados à herança genética do filho adotivo. De acordo com os pesquisadores, em função disso, o GAA poderia funcionar como uma ferramenta para prevenir possíveis conflitos familiares. Schettini, Amazonas e Dias (2006) afirmam que a participação nos GAA pode contribuir para a prevenção e alívio das dificuldades e ansiedades comuns ao processo de adoção e, por isso, GAA deveriam ser valorizados, especialmente pelo apoio emocional e informacional provido aos participantes, bem como pela possibilidade de orientação de um grupo sobre os aspectos burocráticos da adoção (Scorsolini-Comin et al., 2006).

Pensando-se na importante contribuição que os GAA podem exercer nas famílias por adoção, entende-se a necessidade de que se compreenda os processos gerados nesses grupos para que se possa avaliar seus efeitos a longo prazo para as famílias participantes. Nesse sentido, a parceria entre Universidade e sociedade civil 
aparece como uma alternativa importante para proporcionar a atenção especializada necessária para o suporte a ser oferecido nesse contexto. A partir disso, este estudo teve como objetivo descrever a experiência de coordenação de um grupo de apoio à adoção em parceria entre universidade com uma ONG Sul-brasileira durante o período de um ano.

\section{RELATO DA EXPERIÊNCIA}

O Núcleo de Pesquisa e Intervenção em Famílias com Bebês e Crianças (NUFABE) da Universidade Federal do Rio Grande do Sul, iniciou o contato com a GAA, a fim de conhecer melhor a demanda das famílias por adoção, visto que vinha desenvolvendo projetos de pesquisa na área. $\mathrm{O}$ contato aconteceu através do presidente da ONG que já desenvolvia esses grupos em uma cidade da região metropolitana em parceria com o curso de psicologia em uma universidade privada. O objetivo da ONG nessa parceria era manter o trabalho oferecido às famílias com a mediação de profissionais e estudantes qualificados para a realização das intervenções.

No modelo já estabelecido pela ONG, ocorriam dois grupos simultaneamente: um com os pais e outro com as crianças. Os grupos se configuravam como grupos abertos e contavam com a participação voluntária de pais que esperavam pela adoção, pessoas que já adotaram e traziam ou não seus filhos para os encontros, bem como pessoas interessadas pela temática da adoção por diferentes motivos, como histórias de adoção na família e interesse acadêmico.

\section{DESCRIÇÃO DOS PARTICIPANTES}

O número (média de 20 participantes por encontro) e as características dos participantes eram variadas, já que compunham o grupo voluntariamente. Em geral, famílias que compareciam às reuniões desse grupo estavam em diferentes estágios do processo de adoção: passando pelos momentos burocráticos iniciais ou no período de espera após a habilitação, pelo período inicial de adaptação à criança, pelo pós-adoção recente ou com adoções já formalizadas há bastante tempo. Esses grupos eram constituídos por pessoas de variados estados civis, orientações sexuais e níveis socioeconômicos.

Para mediar os grupos, quatro psicólogas, estudantes de pós-graduação, a maioria também com formação clínica, participaram como coordenadoras, e uma professora como supervisora. A equipe também contava com o auxílio de estudantes de graduação em psicologia. Os últimos cinco encontros do grupo das crianças foram mediados por uma musicoterapeuta, doutoranda em psicologia.

\section{DESCRIÇÃO DOS ENCONTROS}

As reuniões ocorreram mensalmente na cidade de Porto Alegre, no período entre 2016 e 2017. O tópico de cada encontro era previamente informado aos participantes através do convite pelas redes sociais. A universidade onde os encontros ocorreram proveu duas salas amplas, uma para os adultos, com cadeiras e um retroprojetor, e outra para as crianças, organizada com um grande carpete, almofadas, brinquedos e material para desenhos e atividades gráficas.

Silva et al. (2022). (Re)construindo vínculos: relato de experiência de um grupo de apoio à adoção. https://doi.org/10.32467/issn.2175-3628v23n1a14 
Para prover estímulo e abertura nos participantes, considerando a temática escolhida, foram utilizadas apresentações em PowerPoint, filmes curtos e dinâmicas de grupo. Também, durante o encontro, os coordenadores pretenderam dar uma compreensão empática e clarificar algumas dúvidas sobre os aspectos psicológicos da adoção. Os coordenadores e a supervisora encontravam-se semanalmente para discutir os encontros anteriores e preparar as reuniões futuras. Esses momentos promoveram reflexão, supervisão, estudo, e preparação das coordenadoras.

Conforme os participantes chegavam para o grupo de apoio, eram designados a esperar, crianças e adultos, todos na mesma sala. No horário combinado para início dos encontros, dois psicólogos acompanhavam as crianças para a sala especificamente preparada para eles e dois permaneciam com os adultos. Os encontros tinham a duração aproximada de uma hora e 30 minutos. No final, os participantes, crianças e adultos, se reuniam mais uma vez para discutir, de acordo com as experiências obtidas, o tema do próximo encontro.

O relato dos grupos priorizou as atividades realizadas com os adultos, uma vez que nos grupos das crianças, muitas vezes ocorreu um momento mais recreativo e não reflexivo, especialmente dependendo da idade e número de crianças participantes no dia do evento. $\mathrm{O}$ tema do primeiro encontro foi decidido pela equipe de coordenação em conjunto com a direção da ONG. Na Tabela 1 é possível observar os temas trabalhados nos grupos e as técnicas utilizadas para o seu desenvolvimento.

\section{Tabela 1}

Descrição dos temas, objetivos e técnicas de cada encontro.

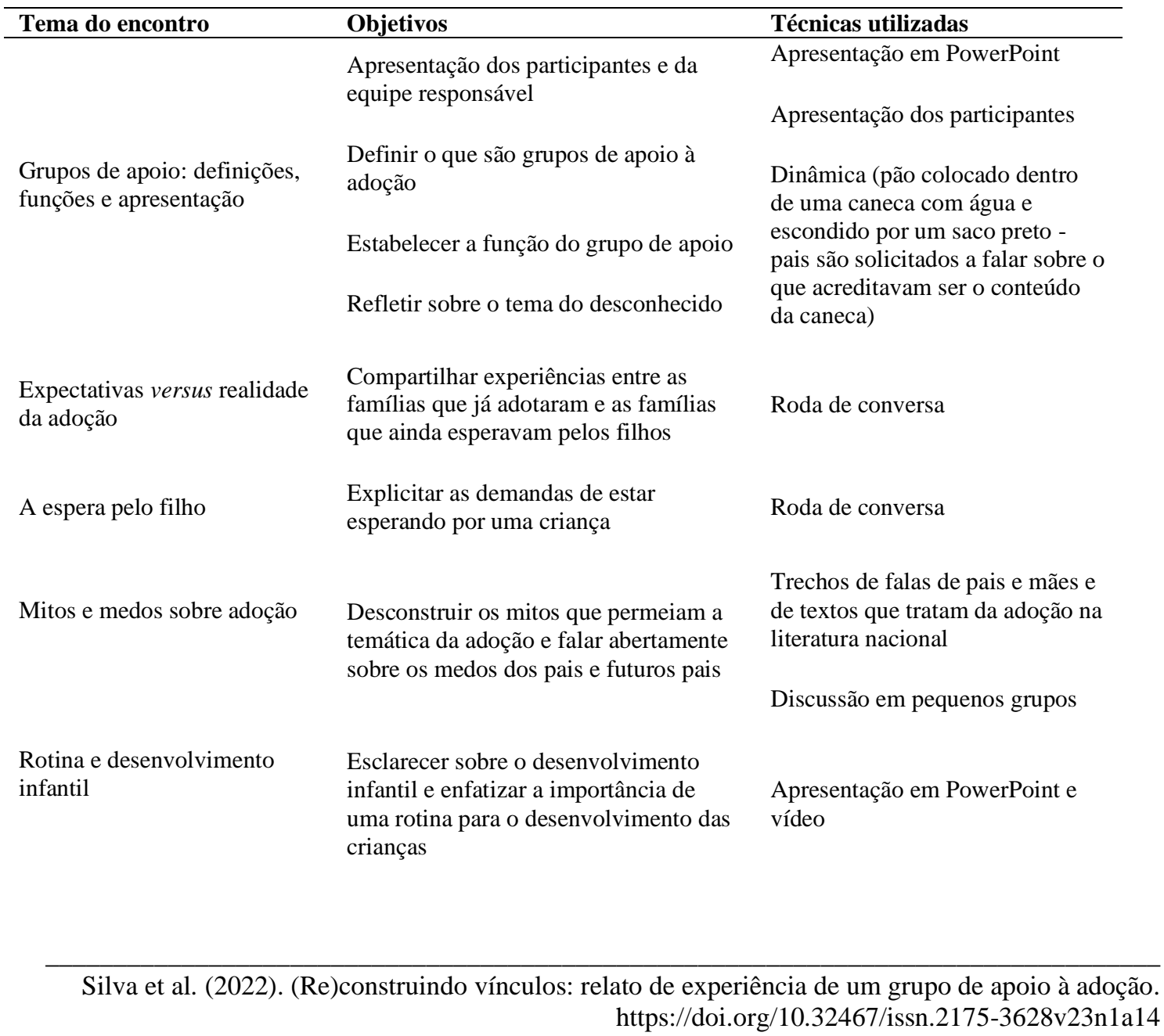




\begin{tabular}{lll}
\hline Tema do encontro & Objetivos & Técnicas utilizadas \\
\hline Percurso da adoção & $\begin{array}{l}\text { Compartilhar sua experiência de adoção } \\
\text { ou de espera pela adoção, considerando } \\
\text { altos e baixos do processo }\end{array}$ & $\begin{array}{l}\text { Desenho representando o } \\
\text { percurso da adoção }\end{array}$ \\
$\begin{array}{l}\text { Dissolução da adoção } \\
\text { (Devolução) }\end{array}$ & $\begin{array}{l}\text { Falar abertamente sobre os desejos de } \\
\text { dissolução da adoção e a superação } \\
\text { desses sentimentos }\end{array}$ & Roda de conversa \\
Amor & $\begin{array}{l}\text { Trabalhar como se dá a construção dos } \\
\text { novos vínculos afetivos nas famílias por } \\
\text { adoção }\end{array}$ & $\begin{array}{l}\text { Vídeos gravados com as crianças } \\
\text { do grupo sobre o que é o amor }\end{array}$ \\
$\begin{array}{l}\text { Formação e rompimento de } \\
\text { vínculos }\end{array}$ & $\begin{array}{l}\text { Esclarecer sobre as experiências de } \\
\text { rompimento precoce de vínculos } \\
\text { vivenciadas pelas crianças e como isso } \\
\text { impacta a formação dos novos vínculos }\end{array}$ & $\begin{array}{l}\text { Apresentação em PowerPoint e } \\
\text { roda de conversa }\end{array}$ \\
\hline $\begin{array}{l}\text { Tira dúvidas sobre adoção } \\
\text { Esclarecer as dúvidas que surgiram nos }\end{array}$ & $\begin{array}{l}\text { Exposição da equipe conforme as } \\
\text { dúvidas apresentadas }\end{array}$ \\
\hline
\end{tabular}

\section{EVOLUÇÃO DOS TEMAS TRABALHADOS}

O primeiro encontro teve como objetivo esclarecer sobre como se daria o funcionamento do grupo em Porto Alegre, haja vista que alguns participantes já frequentavam outro grupo da mesma ONG em outra cidade. A ideia inicial foi motivar os participantes a permanecerem no GAA visando à possibilidade de continuidade do trabalho com estas famílias, mesmo que o grupo se configurasse como aberto.

A dinâmica proposta no primeiro dia teve como objetivo fomentar a reflexão sobre o fenômeno do desconhecido. A discussão que seguiu teve como tema principal as expectativas e medos que permeiam o universo da adoção que, muitas vezes, são maiores e mais assustadoras do que a realidade que vivenciam em suas famílias. Ao finalizar o primeiro encontro, abriu-se a discussão para o tema do segundo encontro que, dando seguimento ao que foi trabalhado na dinâmica do pão, decidiu-se que se falaria sobre as expectativas em relação à adoção em contraponto com a realidade para aqueles que já receberam seus filhos.

Essas expectativas foram corroboradas pelos adotantes, durante o segundo encontro, quando relataram que essa adaptação só era mesmo possível após a chegada da criança. Eles também puderam falar de como imaginavam que seriam como pais, principalmente em relação aos limites que colocariam, e do quanto isso não se confirmou após a chegada das crianças. Também falaram do quanto a adaptação vai depender da criança real que vai estar com eles e relataram experiências sobre o que imaginavam que seria conviver com seus filhos e das atividades que com eles fariam. Os pais e mães trouxeram suas experiências relatando sentimentos de frustração pelas expectativas não realizadas, mas também relatando outras experiências de surpresa e aprendizado com os filhos. Ao final do encontro, a equipe percebeu que a principal demanda do grupo parecia ser as expectativas em relação à espera. Então, combinou-se com as famílias que o próximo encontro trataria disso.

Neste terceiro dia, a equipe propôs uma troca de experiências visto que o grupo era composto tanto de pessoas que estavam esperando por seus filhos, quanto por pais e 
mães que já haviam adotado. Além disso, o tempo de adoção variava bastante, desde poucas semanas a anos de convivência com os filhos. Propôs-se que os pais e mães em espera pela adoção iniciassem seus relatos sobre as expectativas em relação a esse momento. O período de espera pelo filho foi relatado pelos participantes como um período de instabilidade. Muitos também relataram um sentimento de abandono por parte do judiciário.

Não existem políticas específicas de acompanhamento dessas pessoas após a inserção no cadastro nacional de adoção e, até que recebam o telefonema com a notícia da chegada dos seus filhos, e os pais referiram sentirem-se sozinhos durante esse percurso. Alguns relataram terem feito movimentos de buscar as técnicas para saberem sobre a sua situação na lista de espera, outros relataram não terem tantas expectativas em relação ao momento da chegada. Percebeu-se que as expectativas parecem proporcionais ao tempo decorrido de espera.

Muitos pais falaram das dificuldades de esperar uma criança sem características definidas. Ou que a preparação era dificultada por não saberem exatamente nem mesmo a idade dos futuros filhos, o que gerava muitos medos em torno das ideias préconcebidas sobre adoção. Com isso, decidiu-se em conjunto que o tema do próximo encontro seriam os mitos e medos que permeiam essas famílias.

Nesse quarto encontro, a equipe levou para os pais trechos de falas de outros pais e mães adotivos retirados da literatura nacional e de entrevistas realizadas pelo grupo de pesquisa acerca dos mitos e medos quanto à adoção. Os participantes foram separados em pequenos grupos para discutirem esses trechos e depois levarem a discussão ao grande grupo. Muitos dos relatos compartilhados pelas famílias que já adotaram se relacionavam às dificuldades em implementar uma rotina na vida das crianças. Os pais que já receberam seus filhos falaram bastante sobre as dificuldades com as rotinas e cuidados básicos das crianças como higiene e tarefas escolares. A partir disso, a equipe propôs aos pais que se abordasse no próximo encontro questões relativas ao desenvolvimento infantil e a necessidade de uma rotina para facilitar o vínculo paisfilhos.

No quinto encontro, utilizaram-se recursos audiovisuais para trazer alguns conhecimentos teóricos para os pais sobre e esclarecer dúvidas que surgiam. Tratou-se nesta exposição dos marcos desenvolvimentais e de como isso pode não se aplicar a todas as crianças em função das vivências de negligência, maus-tratos e institucionalização. Para finalizar, a equipe expôs a importância de uma rotina para que a criança saiba o que esperar dos cuidados dos pais. A discussão gerada a partir dessa exposição concluiu que cada família precisa passar por um percurso específico na construção de uma rotina que se adapte a sua própria realidade e às necessidades específicas de cada criança. Nesse sentido, decidiu-se ao final que seria importante falar dos percursos vivenciados em todo o processo de adoção.

Para o sexto encontro, a equipe dividiu os participantes em pequenos grupos e solicitou que confeccionassem um desenho que representasse o percurso da adoção, na sua perspectiva. Foi possível perceber que, para os participantes, o percurso da adoção era marcado por obstáculos que, por vezes, os colocavam em dúvida sobre o sucesso da adoção. As dificuldades enfrentadas no caminho os faziam pensar, diversas vezes, sobre a possibilidade de dissolução da adoção, marcando o fracasso do processo como um todo. A partir disso, decidiu-se tratar, no próximo encontro, sobre a temática do fracasso da adoção, ainda chamado de devolução. 
A ideia principal do sétimo encontro, sobre dissolução da adoção (devolução), era permitir que os pais falassem abertamente sobre esses pensamentos. Sabe-se que muitos adotantes, em algum momento, frente às dificuldades de adaptação aos filhos, pensam em desistir da adoção por não se sentirem capazes de enfrentar esses desafios. Com isso, os pais puderam expor suas maiores angústias e ouvir de outros pais, que já estavam há mais tempo com seus filhos, que as dificuldades tendem a ser passageiras e que, com o auxílio adequado é possível ter sucesso na tarefa da parentalidade. Além disso, a discussão também gerou reflexão sobre o processo de construção dos vínculos com o os filhos, que é um processo gradual. Ao final desse encontro, as crianças foram convidadas a expor o que estavam vivenciando no grupo e ouvir um pouco das vivências dos pais. Nesse momento, aconteceu um movimento interessante de proposição do tema do próximo encontro pelas próprias crianças: falar sobre o amor. Como o amor é importante para se ter sucesso na adoção.

A equipe, comovida com o movimento sugerido pelas crianças, se propôs trabalhar, a temática a partir do conceito da palavra amor, no oitavo encontro. Foi realizada uma breve apresentação e os pais que já haviam adotado foram convidados a relatarem quando sentiram que amavam seus filhos. A ideia foi enfatizar que o amor entre pessoas que não se conhecem e já tem uma história de outros vínculos é um processo que precisa ser construído e cultivado. Muitos relatos giraram em torno das dificuldades das crianças em estabelecer novos vínculos em função de vivências anteriores. Com isso, decidiu-se que o próximo encontro trataria do efeito do rompimento precoce de vínculos das crianças para a relação que viria a se estabelecer.

$\mathrm{O}$ tema do nono encontro preparado pela equipe foi, portanto, a formação e rompimento de vínculos afetivos com o objetivo de esclarecer aos pais que as vivências traumáticas de abandono e privação de afeto deixam marcas na vida das crianças e podem influenciar a forma como elas vão estabelecer novas relações. Muitos pais compartilharam a história de seus filhos adotivos e refletiram sobre o reflexo dessas histórias no comportamento das crianças. Para o décimo e último encontro, ficou planejada uma retrospectiva do que foi abordado durante o ano.

Ao final do ano de 2017 foi encerrado o vínculo com a ONG. No entanto, a divulgação da notícia nas redes sociais atingiu um público muito maior do que o esperado, contando com a participação de mais de 80 pessoas. Com isso, a equipe precisou se dividir em duas salas e decidiu-se atender às dúvidas dos participantes sobre adoção. Muitos dos presentes eram estudantes interessados pela temática e profissionais de cidades próximas que trabalhavam na assistência às crianças.

\section{DISCUSSÃo}

Os GAA têm sido relatados como uma modalidade importante de suporte tanto para candidatos postulantes à adoção, como por pais e mães que já adotaram (Balbino et al., 2015; Bergsund et al., 2018; Burke et al., 2018; Cavarzan \& Camargo, 2017; Menezes \& Dias, 2018; Morelli et al., 2015). Na experiência relatada, o grupo pareceu oferecer um ambiente seguro para o compartilhamento de experiências. Os postulantes à adoção que ainda estão na espera encontraram um espaço para preparação e elaboração de sua parentalidade adotiva. Por se configurar como um grupo heterogêneo, ouvir o relato daqueles que já adotaram pareceu ser um bom mecanismo para o esclarecimento de dúvidas e alívio da ansiedade dos que esperavam. Por outro lado, as famílias que já

Silva et al. (2022). (Re)construindo vínculos: relato de experiência de um grupo de apoio à adoção. https://doi.org/10.32467/issn.2175-3628v23n1a14 
adotaram relataram alívio ao ouvir aqueles que vivem situações e sentimentos semelhantes aos seus. O trabalho no grupo permitiu o confronto das expectativas relacionadas à adoção com aquilo que é de fato vivenciado - a parentalidade real - nas diferentes famílias, o compartilhamento de experiências e o aprendizado conjunto.

Dentre os temas relevantes de serem discutidos em grupos de adoção, diversos autores (Costa et al., 2011; Menezes \& Dias, 2018; Scorsolini-Comin et al., 2006) destacam a ansiedade e a angústia frente à longa espera no cadastro da adoção, a burocracia dos processos legais e o medo de perder o filho para a família biológica, por exemplo. Neste tocante, o esclarecimento de dúvidas, de modo a acalmar medos e inseguranças referentes à situação que o indivíduo está passando no momento, são reconhecidos como os benefícios da interação em grupos de apoio (Balbino et al., 2015), que apareceu também no presente relato. Somado a isso, por meio do diálogo em um grupo de apoio é possível atingir objetivos importantes como, por exemplo, a superação de ideias estereotipadas sobre a adoção, reduzindo estigmas (Sequeira \& Stella, 2014; Scorsolini-Comin et al., 2006; Morelli et al., 2015; Fiorott et al., 2019).

Percebeu-se nos relatos dos participantes que os vínculos que se estabeleceram entre as famílias adotivas e as crianças dependiam de como os adultos conseguiam elaborar sua parentalidade entre o idealizado e o real e as ambivalências que permeiam essa vivência. Nesse sentido, Menezes e Dias (2018) referem que tanto os pretendentes criam expectativas em relação ao futuro filho, como as crianças criam expectativas quanto aos futuros pais, algo também referido pelas crianças em alguns dos encontros do grupo.

Ainda, o auxílio na compreensão dos desafios futuros relacionados à adoção que os grupos de apoio podem fornecer é fundamental para a melhor adaptação familiar, podendo, inclusive, prevenir situações de devolução da criança adotada (Morelli et al., 2015). Por meio da sensibilização e preparação dos futuros pais para as questões que permeiam a parentalidade e a filiação, os grupos podem atuar como uma ferramenta de prevenção dos conflitos futuros com a criança adotada (Sequeira \& Stella, 2014). Além disso, os grupos podem atuar no reconhecimento de problemas ou dificuldades atuais, e, através do suporte provido, tem-se um meio para a recuperação da situação (Reis, 2014), ou de perceber que talvez seja um sentimento que permeia boa parte dos pais durante o processo da adoção, como foi referido no presente relato.

Como exemplos, o grupo pode ser efetivo no manejo dos problemas comportamentais advindos de abusos ou negligências anteriores à adoção, que podem atuar como estressores no relacionamento entre os pais adotivos e a criança (Schwartz et al., 2014) ou frente às práticas educativas utilizadas, proporcionando uma reavaliação de seus métodos, repercutindo positivamente na relação familiar (Cavarzan \& Camargo, 2017). Percebe-se que a participação em grupos de apoio mostra-se como um preditor de sucesso nas adoções (Schwartz et al., 2014), especialmente porque pode-se pensar que pais que se mostram dispostos a pedir ajuda, possam apresentar melhores condições para sucesso tanto nas adoções quanto em outros contextos de parentalidade (Hoghughi, 2004; Resmini, 2018). As redes de apoio sociais, ou seja, os recursos reconhecidos e acionados pela família ao longo do seu desenvolvimento, têm sido associadas à promoção de saúde, no que auxiliam em situações de crise ou nos momentos de transição do ciclo vital, como a chegada dos filhos (Moré \& Crepaldi, 2012).

Ainda, enfatizam-se as potencialidades dos processos grupais. $\mathrm{Na}$ experiência relatada neste artigo, evidenciou-se que os encontros tornaram o grupo um espaço onde era permitido falar sobre os sentimentos, contribuindo para a construção de vínculos e

Silva et al. (2022). (Re)construindo vínculos: relato de experiência de um grupo de apoio à adoção. https://doi.org/10.32467/issn.2175-3628v23n1a14 
para a desmistificação de vários temas concernentes à adoção e à parentalidade. Os participantes da experiência demonstraram grande habilidade de vinculação e envolvimento, especialmente através das escolhas de temas a serem tratados. A vivência nos grupos de apoio à adoção mostrou-se, portanto, como aspecto positivo aos integrantes e como promotor do bem-estar destas famílias. Consoante a isso, Scorsolini-Comin e Santos (2008) destacam como vantagem dos grupos de apoio à adoção a possibilidade de aprendizado e de trocas de experiência com o outro. Isto porque é possível reconhecer na experiência alheia aquilo que, por vezes, não se é capaz de identificar em si mesmo. Através dos relatos, os frequentadores de um grupo de apoio tornam-se mais capazes de se desfazer de preconceitos, proporcionando uma mudança gradual em relação às concepções sobre a adoção, por exemplo, em modificações do perfil do adotando referentes à adoção tardia (Fiorott et al., 2019), mas também à adoção inter-racial ou de grupo de irmãos (Costa et al., 2011). Os grupos podem funcionar, portanto, como um espaço no qual os pais são convidados a construir o "lugar" do filho adotivo no psiquismo parental, elaborando o luto pelo filho ideal e abrindo caminho para a chegada do filho real (Morelli et al., 2015).

$\mathrm{O}$ acolhimento das necessidades pessoais, somado à criação de parcerias entre os participantes, atuam como fator de fortalecimento emocional e diminuição de sofrimentos (Duarte et al., 2013), fazendo da inserção em grupos de apoio à adoção uma ação recomendável. No estudo de Costa e Kemmelmeier (2013) a participação em um grupo operativo possibilitou aos pais que esperavam pela adoção de seus filhos, dividirem seus conflitos, e refletirem acerca de mudanças potenciais na vivência de espera do filho. Contudo, os autores defendem a importância do acompanhamento dos pais por uma equipe preparada, destacando a inserção da Psicologia. Também Fiorott et al. (2015) enfatizaram a atuação de psicólogos nos grupos, no que estes possibilitam a ampliação de concepções subjetivas historicamente instituídas nos âmbitos sociais, individuais e até mesmo inconscientes, o que permite a construção de novos sentidos de cuidado, proteção e família.

Muitas vezes é através destes grupos que os postulantes à adoção passarão pela preparação necessária (Morelli et al., 2015; Menezes \& Dias, 2018), a qual, conforme obrigatoriedade da legislação, deve ser mediada por profissionais capacitados, como psicólogos e assistentes sociais (Lei 12.010, 2009). Além de constituírem uma rede de apoio paralela à família, os grupos podem facilitar o acesso a profissionais especializados e a materiais específicos e bem embasados (Balbino et al., 2015). Por outro lado, assim como os grupos proporcionam espaços de reflexão e amadurecimento do projeto adotivo, estes podem não ser suficientes para dar conta de aspectos subjetivos e emocionais relacionados à complexidade do desejo envolvido na adoção (Menezes \& Dias, 2018), demandando outras intervenções.

Deve-se atentar, portanto, às situações que extrapolam as capacidades dos grupos. Algumas vezes é possível que os profissionais identifiquem demandas que necessitam um acompanhamento mais próximo e especializado. No grupo descrito no presente estudo, uma família precisou de encaminhamento para uma psicoterapia a pais (Machemer, 2020). Intervenções no pós-adoção têm o potencial de proteger a família de um possível fracasso da adoção (Burke et al., 2018), questão que o grupo de apoio pode identificar. A psicoterapia, nesse caso, auxiliou a promover a sensibilidade parental em uma família com muitas dificuldades na adaptação, facilitando o processo de transição para a parentalidade e da consolidação dos vínculos (Machemer, 2020). 
Por fim, destaca-se que ações de extensão no âmbito acadêmico, como a desenvolvida e relatada neste artigo, contribuem não apenas ao atendimento de demandas sociais, como também à formação acadêmica dos graduandos e pósgraduandos envolvidos. As atividades relatadas foram realizadas por pesquisadores e voluntários do Núcleo de Pesquisa e Intervenção em Famílias com Bebês e Crianças (NUFABE) que, desde o ano de 2016, têm se debruçado em investigar a transição à parentalidade adotiva. Assim, a extensão universitária corresponde a um processo educativo, em articulação permanente com a pesquisa. Afinadas à Política Nacional de Extensão Universitária (2012), atividades como as desenvolvidas promovem a interação entre universidade e sociedade, atendendo às demandas do contexto social, em especial, as relacionadas à adoção, oportunizando um espaço necessário aos pretendentes à adoção e famílias adotivas, como também de aprendizado aos graduandos e pósgraduandos. Além disso, a atividade proporcionou a oportunidade de aproximar a pesquisa acadêmica da realidade vivenciada pelas famílias nesse contexto e serviu como base para a construção de dois grandes projetos de pesquisa que vêm contribuindo para a construção e fortalecimento de conhecimentos sobre adoção (Frizzo et al., 2016; Frizzo et al., 2019).

\section{CONSIDERAÇÕES FINAIS}

O presente estudo teve como objetivo descrever a experiência de coordenação das atividades com pais de um GAA em uma parceria entre Universidade e organização da sociedade civil. A partir da experiência relatada, foi possível perceber que os GAA parecem ser um dispositivo importante para facilitar a transição para parentalidade por adoção em diferentes momentos do processo de adoção.

Enfatiza-se a importância da mediação profissional especializada nesses grupos de apoio a fim de fornecer um espaço de compartilhamento de experiências e aprendizado livre de julgamentos, facilitando a expressão de vulnerabilidades dos pais e futuros pais. Com isso, a experiência do GAA pareceu contribuir para um alívio das angústias das famílias e também para fortalecer a comunicação intrafamiliar, já que era oferecido um espaço para que se ouvisse a demanda das crianças em relação aos temas que permeiam a adoção. Ainda, o GAA pareceu aumentar a rede de apoio na medida em que os aproximou de um serviço oferecido pela Universidade.

Como limitações, por ter sido esta a primeira experiência das coordenadoras com um GAA, a mediação dos grupos pode ter sido dificultada em função da ausência de uma metodologia específica, e também pela falta de relato de outras experiências semelhantes. Além disso, não foi possível fazer uma avaliação dos efeitos do grupo para os pais por não se ter utilizado uma medida pré e pós-intervenção, sendo a intervenção avaliada somente através do feedback dos participantes.

Por fim, apesar das limitações encontradas, destaca-se a relevância da experiência relatada por explicitar a importância dos processos grupais ao se abordarem questões relativas à adoção e à parentalidade nesse contexto. Foi possível evidenciar a potência do grupo ao permitir que sentimentos fossem relatados em um ambiente acolhedor e sem julgamentos, o que contribuiu para a desmistificação de temas relacionados à adoção e, possivelmente, para a construção e fortalecimento dos vínculos com as crianças e com outras famílias que vivenciam situações semelhantes. 
Ainda, pode-se pensar que experiências futuras de grupos envolvendo famílias por adoção possam contar com membros em diferentes etapas do processo adotivo, como o relatado neste artigo. Essas diferenças de tempos permitiram que as famílias pudessem aprender e refletir sobre questões que já vivenciaram ou que ainda viriam a vivenciar nas suas histórias com seus filhos e filhas.

Também, poder trabalhar com temas escolhidos pelas próprias famílias faz com que a atuação dos profissionais seja pautada nas necessidades reais daqueles que se beneficiam das intervenções. O que contribui não somente para o benefício das famílias, mas também no próprio engajamento do grupo com a proposta, o que também pode ser observado com a presença das famílias nos encontros subsequentes.

Por fim, destaca-se a importância das atividades de extensão acadêmica para a formação do docente/pesquisador. Sendo a pesquisa no Brasil ainda muito associada ao ambiente universitário, as atividades de extensão se mostram como um bom recurso de avaliação das demandas sociais a fim de aproximar a pesquisa da realidade das famílias brasileiras. Somado a isso, as parcerias estabelecidas entre universidade e sociedade valorizam as famílias enquanto co-construtoras de soluções para suas demandas.

\section{REFERÊNCIAS}

Alvarenga, L. L. D., \& Bittencourt, M. I. G. F. (2013). A delicada construção de um vínculo de filiação: o papel do psicólogo em processos de adoção. Pensando Famílias, 17(1), 41-53. Disponível em: http://pepsic.bvsalud.org/scielo.php?script=sci_arttext\&pid=S1679494X2013000100005\&lng=pt\&tlng=pt

Associação Nacional de Grupos de Apoio à Adoção [ANGAAD] (2019). Regimento Interno. https://www.angaad.org.br/portal/institucional/regimento-interno-angaad/

Balbino, F. S., Yamanaka, C. I., Balieiro, M. M. F. G., \& Mandetta, M. A. (2015). Grupo de apoio aos pais como uma experiência transformadora para a família em unidade neonatal. Escola Anna Nery, 19(2), 297-302. https://doi.org/10.5935/14148145.20150040

Bergsund, H. B., Drodz, F., Hansen, M.B., \& Jacobsen, H. (2018). Pre-adoption training: Experiences and recommendations from adoptive parents and course trainers. Children and Youth Services Review, 95, 282-289. https://doi.org/10.1016/j.childyouth.2018.11.008

Burke, R.V., Research Team, T. P. G., Schlueter, C., Bader, E., \& Authier, K. J. (2018). Post-adoption services for high-risk families and their children: Preliminary results of a state-wide intervention. The American Journal of Family Therapy, 46(2), 122138. https://doi.org/10.1080/01926187.2018.1450687

Cavarzan, D. F. K., \& Camargo, D. (2017). Grupo de apoio social para mães de crianças diagnosticadas com TDAH. International Journal of Developmental and Educational Psychology, 3(1), 93-101. https://doi.org/10.17060/ijodaep.2017.n1.v3.978

Costa, L. T. M., \& Kemmelmeier, V. S. (2013). O olhar de futuros pais sobre o processo de adoção. Psicologia Argumento, 31(72), $187-196$. http://dx.doi.org/10.7213/psicol.argum.7619

Costa, L. T. M., Sasson, M. D. H., Bronislawski, T., Tibola, V. B., \& Kemmelmeier, V. S. (2011). Grupo de apoio a pais na fila de espera da adoção. Revista Conexão

Silva et al. (2022). (Re)construindo vínculos: relato de experiência de um grupo de apoio à adoção. https://doi.org/10.32467/issn.2175-3628v23n1a14 
UEPG, 7(2), 240-245. Disponível em: https://revistas2.uepg.br/index.php/conexao/article/view/3722

Duarte, E. D., Silva, D. E., Noelly, B. C., \& Rocha, L. L. B. (2013). Grupos de apoio às mães de recém-nascidos internados em unidade neonatal. Revista da Rede de Enfermagem do Nordeste, 14(3), 630-638. Disponível em: http://www.periodicos.ufc.br/rene/article/view/3507

Fiorott, J. G., Palma, Y. A., \& Ecker, D. D. (2019). Conceito de grupo-dispositivo no apoio à adoção: Desnaturalizando significados instituídos. Ciências Psicológicas, 13(2), 390-397. http://dx.doi.org/10.22235/cp.v13i2.1895.

Frizzo, G. B., Silva, P. S., Resmini, G. F., Schwochow, M. S., Leão, L. C. S., Levandowski, D. C., Lopes, R. C. S., Vieira, M. L., \& Chaves, V. P. (2016). Transição para a parentalidade adotiva: Pesquisa e intervenção. [Projeto de Pesquisa não publicado].

Frizzo, G. B., Silva, P. S., Machemer, R. S., Naddeo, L., Machado, M. S., \& Schwochow, M. S. (2019). Adoção: Início dos novos vínculos. [Projeto de Pesquisa não Publicado].

Hoghughi, M. (2004). Parenting - An introduction. In M. Hoghughi \& N. Long (Eds.). Handbook of parenting: Theory and research for practice. (pp. 7-28). Sage. https://www.doi.org/10.4135/9781848608160

Lei 8.069 de 13 de julho de 1990. (1990). Dispõe sobre o Estatuto da Criança e do Adolescente. da

República. http://www.planalto.gov.br/ccivil_03/leis/18069.htm

Lei 12.010 de 03 de agosto de 2009. (2009). Dispõe sobre adoção; altera as Leis $n^{\circ}$ 8.069, de 13 de julho de 1990 - Estatuto da Criança e do Adolescente, 8.560, de 29 de dezembro de 1992; revoga dispositivos da Lei n o 10.406, de 10 de janeiro de 2002 - Código Civil, e da Conso. Presidência da República. http://www.planalto.gov.br/ccivil_03/LEIS/L8069.htm

Machemer, R. S. (2020). Psicoterapia para pais no pós adoção: Estudo de caso sobre o processo de construção de uma parentalidade sensível (Dissertação de mestrado), Universidade Federal do Rio Grande do Sul.

Menezes, K. L., \& Dias, C. M. S. B. (2018). Compreendendo os fenômenos que emergem nos encontros de pretendentes à adoção. Investigação Qualitativa em Saúde, 2, 315-324. Disponível em: https://www.proceedings.ciaiq.org/index.php/ciaiq2018/article/view/1791

Miller, J. J., Sauer, C., Bowman, K., Thrasher, S., Benner, K., Segress, M., \& Niu, C. (2018). Conceptualizing adoptive parent support groups: A mixed-method process. Adoption Quarterly, 21(1), 41-57. https://doi.org/10.1080/10926755.2017.1387210

Moré, C. L. O. O., \& Crepaldi, M. A. (2012). O mapa de rede social significativa como instrumento de investigação no contexto da pesquisa qualitativa. Nova Perspectiva Sistêmica, 10(43), 84-98. Disponível em: https://www.revistanps.com.br/nps/article/view/265

Morelli, A. B., Scorsolini-Comin, F., \& Santeiro, T. V. (2015). O "lugar" do filho adotivo na dinâmica parental: Revisão integrativa da literatura. Psicologia Clínica, 27(1), 175-194. https://doi.org/10.1590/0103-56652015000100010

Moyer, A. M., \& Goldberg, A. E. (2015). 'We were not planning on this, but ...': Adoptive parents' reactions and adaptations to unmet expectations. Child \& Family Social Work, 22(Suppl 1), 12-21. https://doi.org/10.1111/cfs.12219 
Política Nacional de Extensão Universitária. (2012). Elaborado pelo Fórum de PróReitores de Extensão das Instituições Públicas de Educação Superior Brasileiras. http://www.ufrgs.br/prorext-siteantigo/arquivos-

diversos/PNE_07.11.2012.pdf/view

Reis, M. E. B. T. (2014). Um olhar psicanalítico sobre os grupos de apoio a famílias de drogadictos. Revista da SPAGESP, 15(2), 109-121. Disponível em: http://pepsic.bvsalud.org/scielo.php?script=sci_arttext\&pid=S167729702014000200009

Resmini, G. F. (2018). A construção da parentalidade na adoção tardia: Formação de vínculos e adaptação inicial na adoção de crianças entre três e cinco anos. (Dissertação de mestrado), Universidade Federal do Rio Grande do Sul (UFRGS).

Resolução $N^{o} 289$ de 14/08/2019 (2019). Dispõe sobre a implantação e funcionamento do Sistema Nacional de Adoção e Acolhimento - SNA e dá outras providências. Brasília: Presidência da República. Disponível em: https://atos.cnj.jus.br/atos/detalhar/2976

Schettini, S. S. M., Amazonas, M. C. L. D. A., \& Dias, C. M. D. S. B. (2006). Famílias adotivas: Identidade e diferença. Psicologia em Estudo, 11, 285-293. https://doi.org/10.1590/S1413-73722006000200007

Schwartz, A. E., Cody, P. A., Ayers-Lopez, S. J., McRoy, R. G., \& Fong, R. (2014). Post-adoption support groups: Strategies for addressing marital issues. Adoption Quarterly, 17(2), 85-111. https://doi.org/10.1080/10926755.2014.891544

Scorsolini-Comin, F., Amato, L. M., \& Santos, M. A. (2006). Grupo de apoio para casais pretendentes à adoção: a espera compartilhada do futuro. Revista da SPAGESP, 7(2), 40-50. Disponível em: http://pepsic.bvsalud.org/pdf/rspagesp/v7n2/v7n2a07.pdf

Scorsolini-Comin, F., \& Santos, M. A. (2008). Aprender a viver é o viver mesmo: O aprendizado a partir do outro em um grupo de pais candidatos à adoção. Vínculo, 5(2), 115-130. Disponível em: http://pepsic.bvsalud.org/scielo.php?script=sci_arttext\&pid=S1806$24902008000200003 \& \operatorname{lng}=\mathrm{pt} \&$ nrm=iso\&tlng=pt

Sequeira, V. C., \& Stella, C. (2014). Preparação para a adoção: Grupo de apoio para candidatos. Psicologia: Teoria e Prática, 16(1), 69-78. Disponível em: http://www.redalyc.org/pdf/1938/193830151006.pdf

Silva, P. S. (2018). O processo de construção da parentalidade no contexto da adoção. (Tese de doutorado), Universidade Federal do Rio Grande do Sul (UFRGS).

Silva, P. S., Cassarino-Perez, L., Sarriera, J. C., \& Frizzo, G. B. (2017). A equipe psicossocial na colocação da criança nos processos de adoção. Psicologia: Ciência e Profissão, 37(3), 608-623. https://doi.org/10.1590/1982-3703000382016

Waid, J., \& Alewine, E. (2018). An exploration of family challenges and service needs during the post-adoption period. Children and Youth Services Review, 91, 213-220. https://doi.org/10.1016/j.childyouth.2018.06.017

Weistra, S., \& Luke, N. (2017). Adoptive parents' experiences of social support and attitudes towards adoption. Adoption \& Fostering, 41(3), 228-241. https://doi.org/10.1177/0308575917708702 
Submetido: 02/06/2020

Reformulado: $12 / 08 / 2021$

Aceito: $16 / 08 / 2021$

\section{Sobre as autoras:}

Patricia Santos da Silva é pós-doutoranda do Programa de Pós-graduação em Psicologia da Universidade Federal do Rio Grande do Sul.

Mônica Sperb Machado é doutoranda do Programa de Pós-graduação em Psicologia da Universidade Federal do Rio Grande do Sul.

Monique Schwochow Silberfarb é doutoranda do Programa de Pós-graduação em Psicologia da Universidade Federal do Rio Grande do Sul.

Roberta Stefanini Machemer é doutoranda do Programa de Pós-graduação em Psicologia da Universidade Federal do Rio Grande do Sul.

Aline Talita Rosa dos Santos é graduanda em Psicologia pela Universidade Federal do Rio Grande do Sul.

Veronica Petersen Chaves é psicóloga do Tribunal de Justiça do Rio Grande do Sul.

Giana Bitencourt Frizzo é docente do Programa de Pós-graduação em Psicologia da Universidade Federal do Rio Grande do Sul.

E-mail de correspondência: patis.psico@gmail.com 